\title{
The genetic control of self-incompatibility in Linanthus parviflorus (Polemoniaceae)
}

\author{
CAROL GOODWILLIE* \\ Department of Botany, Box 355325, University of Washington, Seattle, WA 98195-5325, U.S.A.
}

\begin{abstract}
The genetic control of self-incompatibility (SI) was studied in the spring-flowering annual, Linanthus parviflorus (Polemoniceae). Arrays of full-siblings were cross-pollinated in a fulldiallel design and compatibility relationships were assessed by examining for pollen tube growth in styles. Two to four incompatibility types were observed in each sibship, some types were interincompatible, and reciprocal differences in incompatibility between types were found. The results demonstrated close agreement with expected patterns of incompatibility among full-siblings for sporophytic control of SI with linear dominance. Taken together, these results provide support for sporophytic SI in L. parviflorus. The crossing data presented here are contrasted with results of a previous study indicating gametophytic control of SI in Phlox drummondii, another polemoniaceous species.
\end{abstract}

Keywords: breeding system, Linanthus parviflorus, Polemoniaceae, self-incompatibility.

\section{Introduction}

Self-incompatibility, a mechanism that prevents fertilization by self pollen, is a common feature of higher plants. In most cases, self-incompatibility (SI) has been found to have a simple genetic basis involving a single locus, referred to as the $S$-locus, with multiple alleles. When pollen and stigma express the same allele at the $S$-locus, fertilization does not occur. Two major classes of SI systems have been identified, distinguished primarily by the genetic control of pollen incompatibility (de Nettancourt, 1977). In gametophytic self-incompatibility (GSI), the incompatibility type of the pollen is determined by the $S$-allele of the haploid gamete. Sporophytic self-incompatibility (SSI) differs in that the pollen incompatibility is determined by the diploid $S$-genotype of the sporophyte parent. Dominance hierarchies among $S$-alleles in stigma or pollen expression, or both, are a common feature of SSI systems (de Nettancourt, 1977). Nonlinear dominance, in which the dominance level of an allele may depend upon the particular combination of alleles (e.g. all alleles are codominant in $S_{1} S_{2}$ and $S_{1} S_{3}$ genotypes, but $S_{2}$ is dominant to $S_{3}$ in the $S_{2} S_{3}$ heterozygote), has also been described in SSI

\footnotetext{
*E-mail: goodwill@u.washington.edu
}

systems (Sampson, 1958; Thompson \& Taylor, 1966). Because of dominance, $S$-locus homozygotes may occur in SSI, whereas in GSI all individuals are expected to be heterozygous.

Sporophytic SI has been previously identified in only six plant families. The genetic control of SI has been studied extensively in the Brassicaceae (e.g. Bateman, 1954; Ockendon, 1974; Ford \& Kay, 1985) and Asteraceae (e.g. Gerstel, 1950; Crowe, 1954; Davidson \& Stace, 1986), and more recently, has been described in the Convolvulaceae (Martin, 1968; Kowyama et al., 1980), Betulaceae (Thompson, 1979), Caryophyllaceae (Lundqvist, 1979, 1990) and Sterculiaceae (Jacob, 1980). Gametophytic SI appears to be the more common form, known in 14-17 plant families (Charlesworth, 1988).

Gametophytic SI has been reported in the Polemoniaceae (Levin, 1975, 1993). The Polemoniaceae is a large family comprising mostly annual and perennial herbs of North America. Despite a long history of interest in the diverse pollination mechanisms and reproductive biology of the family (e.g. Grant \& Grant, 1965; Levin, 1972; Schoen, 1982; Galen \& Stanton, 1989; Campbell et al., 1991), and despite the prevalence of SI in the Polemoniaceae [found in at least eight of the 18 genera (Grant \& Grant, 1965)], the genetic basis of SI has been studied in only a single species, Phlox drummondii (Levin, 
1993). Based upon incompatibility relationships among self-siblings, Levin concluded that SI in $P$. drummondii was gametophytic. Here I investigate the genetic basis of SI in another polemoniaceous species, Linanthus parviflorus, by examining incompatibility relationships among full-siblings.

Experimental crosses among full-siblings have been used extensively for elucidating the genetic basis of SI. Expectations for incompatibility relationships among full-siblings (assuming that parents are heterozygotes and share no $S$-alleles) differ for GSI and SSI in several respects (Richards, 1986). First, in GSI, individuals with one $S$-allele in common are semicompatible; that is, half of the pollen grains (those not bearing the allele common to the two mating partners) are compatible. In a full-sibling progeny array, four incompatibility types are expected in equal frequencies (Fig. 1a). In SSI, the four expected $S$-genotypes in a full sibship may comprise two, three or four incompatibility types, depending upon dominance interactions among $S$-alleles (Fig. 1b-d). When dominance results in three incompatibility types a $2: 1: 1$ ratio is expected in the progeny, with the incompatibility type that represents two $S$-genotypes twice as frequent as the others. In SSI, an incompatibility type may be fully interincompatible with others bearing one $S$-allele in common, whereas in GSI, an incompatibility type is either fully or semicompatible with all others. In GSI, incompatibility between two individuals does not depend upon the direction of the cross (which individual serves as the male or female parent), whereas in SSI, individuals bearing one $S$-allele in common may show reciprocal differences in incompatibility when cross-pollinated in both directions (Fig. 1b, c, shaded cells). This results when dominance differs in the two tissues.

The results of crosses between full-siblings in $L$. parviflorus indicate that $\mathrm{SI}$ in this species is sporophytic. Although SI is now thought to have evolved several times in the history of angiosperms (Matton et al., 1994; Uyenoyama, 1995), distinct GSI and SSI systems have never been found within a family (Charlesworth, 1985; Matton et al., 1994). Therefore,
Fig. 1 Expected patterns of incompatibility among full-sibling progeny of the cross $S_{1} S_{2} \times S_{3} S_{4}$. + denotes compatible cross; - denotes incompatible cross; \pm denotes semicompatible cross. (a) One-locus GSI. Incompatibility types that share one $S$-allele are semicompatible. (b-d) One-locus SSI. Many patterns of incompatibility are possible, depending upon dominance interactions among $S$-alleles. Examples are given for four (b), three (c) or two (d) incompatibility types. Reciprocal differences in incompatibility between types are indicated by shaded cells. $=$ denotes codominance; $>$ denotes dominance. Note that in (c), with three incompatibility types, the frequency of type A progeny is expected to be twice that of $\mathrm{B}$ or $\mathrm{C}$, whereas in all other examples, expected frequencies of all types are equal.
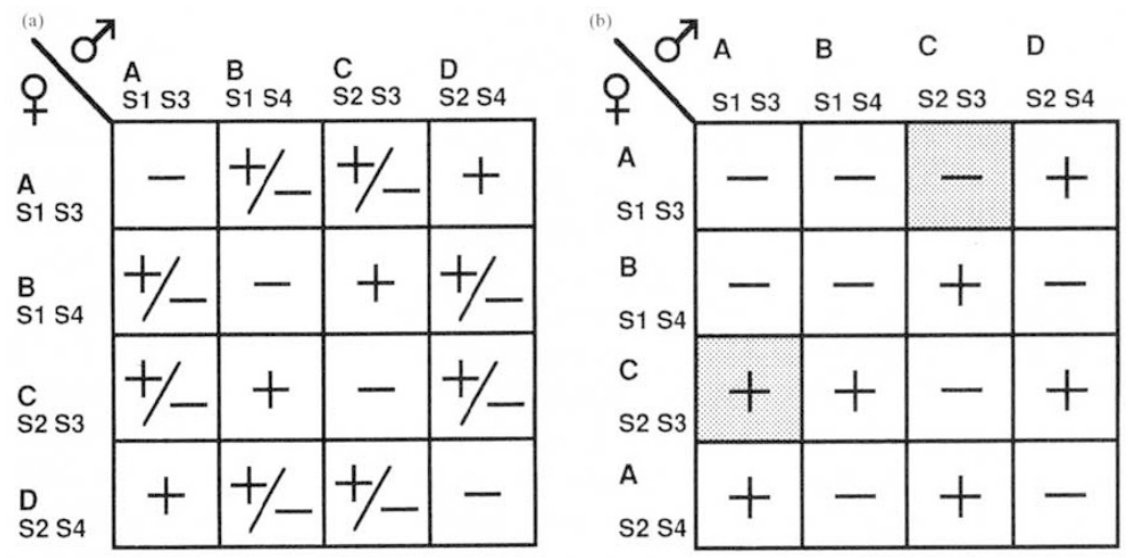

Dominance hierarchies

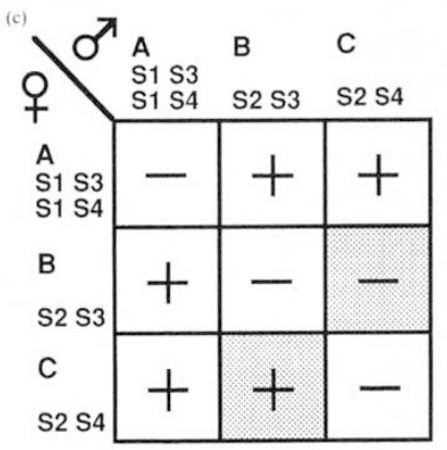

Dominance hierarchies

Pollen: $\mathrm{S} 1=\mathrm{S} 4>\mathrm{S} 3>\mathrm{S} 2$

Stigma: $\mathrm{S} 1=\mathrm{S} 4=\mathrm{S} 3>\mathrm{S} 2$

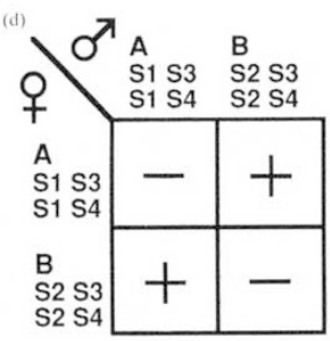

Dominance hierarchies

Pollen: $\mathrm{S} 1=\mathrm{S} 2>\mathrm{S} 3=\mathrm{S} 4$ Stigma: $\mathrm{S} 1=\mathrm{S} 2=\mathrm{S} 3=\mathrm{S} 4$ 
the contrasting conclusions drawn from data for $P$. drummondii and $L$. parviflorus are surprising and demand consideration.

\section{Materials and methods}

\section{Species and habitat}

Linanthus parviflorus, a spring annual, is found in open grasslands or wooded areas throughout California (Hickman, 1993). The small pink- or whiteflowered plants bloom from April to late May and are pollinated by beeflies (Bombylius spp.). The current study was carried out on plants derived from a population adjacent to the Litto Ranch in Napa Co., CA.

Grant \& Grant (1965) describe L. parviflorus as self-compatible and nonautogamous, but experimental results presented here indicate that the species is strongly self-incompatible. SI was detected by comparing self- and cross-pollinated flowers for both pollen tube growth and seed-set. In each of five plants from 31 field-collected maternal families, six flowers were brushed with self pollen and two flowers were brushed with a mixture of pollen from two randomly chosen donors. After $24 \mathrm{~h}$, styles were fixed and examined for pollen tubes using the aniline blue staining method with epifluorescent microscopy (Martin, 1959). Pollen tubes were counted in styles of all selfed flowers and in outcrossed flowers on 65 plants. The mean number of pollen tubes for selfed flowers was 0.6 , as compared to a mean of 160.3 in outcrossed flowers. Seed-set was compared in self- and cross-pollinated flowers on 16 plants. Mean seed-set for selfed flowers ( 0.3 seeds per flower) was less than 5 per cent of that in outcrossed flowers $(6.3$ seeds per flower). In similar experiments on plants from several geographically distinct populations of $L$. parviflorus, hand-selfed flowers showed comparably low seed-set. The extremely low levels of pollen tube growth and seed-set observed in selfed flowers indicate the presence of strong SI in L. parviflorus.

\section{Genetic control of SI}

As reported in $P$. drummondii (Levin, 1975, 1993), $L$. parviflorus exhibits cytological features that have been associated with both SSI and GSI. The pollen is binucleate as in most GSI species (Brewbaker, 1957), but the species has a dry stigma and the incompatibility reaction occurs at the stigma surface, properties that are typical of SSI (Heslop-Harrison \& Shivanna, 1977). The genetic control of SI in $L$. parviflorus was investigated by determining patterns of incompatibility in full-sibling progenies of compatible crosses. Evidence bearing on sporophytic vs. gametophytic control consists of: (i) the number of incompatibility types; (ii) presence or absence of intertype incompatibility; and (iii) presence or absence of reciprocal differences in incompatibility. Although GSI can also be distinguished from SSI by the presence of semicompatibility in full-sibling crosses, preliminary experiments indicated that this criterion was too difficult to test efficiently in $L$. parviflorus and was not considered further.

Eleven full-sibships were generated by crossing 11 pairs of compatible individuals. Parental plants were grown in the greenhouse from seeds collected from randomly chosen individuals in the Litto Ranch population. To minimize the possibility that parental pairs would share $S$-alleles, seeds were collected from individuals at least $1 \mathrm{~m}$ apart. Parents were hand cross-pollinated, with one individual serving as the female parent and the other as the pollen donor. Seeds of the crosses were collected and grown in the greenhouse. When progeny began to flower, arrays of 10-17 plants were crossed in a full-diallel design to assess incompatibility relationships in each sibship. Plants were kept in a pollinator-free greenhouse and flowers were hand-pollinated by brushing stigmas with the anthers of the pollen donor. Styles were harvested, prepared and viewed for pollen tubes as described above. Each cross was replicated on two flowers. Compatible and incompatible pollinations were, for the most part, easily distinguishable, with dense growth of pollen tubes $(>100)$ visible on compatible crosses and usually no pollen tubes present in an incompatible cross. When results were ambiguous (between three and 25 pollen tubes present), and in crosses where the outcome of the two replicates did not agree, additional flowers were pollinated to confirm the determination of compatibility. Each cross was scored as compatible $(+)$ or incompatible $(-)$. Individuals were assigned to incompatibility types based on these results.

\section{Computer analysis}

In one-locus GSI, a single pattern of incompatibility relationships among full-sibling progeny of fully compatible parents is expected (Fig. 1a) and therefore one can easily determine whether crossing data are consistent with such a model. However, in SSI, the expected number of incompatibility types and specific patterns of incompatibility among fullsiblings vary depending upon dominance hierarchies among $S$-alleles in the sibship and where dominance is expressed (Fig. 1b-d). To consider the many

(C) The Genetical Society of Great Britain, Heredity, 79, 424-432. 
possible expected outcomes for SSI and to determine whether the crossing data from $L$. parviflonus sibships could in fact be explained by such a model, a computer program was created. Because sibships with two incompatibility types can be readily explained by SSI or GSI (see Discussion) and are therefore not informative, the program addresses only sibships with three or four incompatibility types. When three incompatibility types are observed, the program considers models that predict three incompatibility types in the progeny, as well as the possibility that a fourth type was not sampled. The program contains an algorithm to generate expected results from all possible linear dominance relationships in the four parental $S$-alleles, including models with dominance in pollen only, stigma only, dominance expressed similarly in pollen and stigma, and dominance expressed differently in the two tissues. Parents are assumed to be heterozygous and to share no $S$-alleles. The program then compares the expected results to the observed compatibility relationships and all dominance hierarchies consistent with the experimental results are identified.

\section{Results}

In 95.4 per cent of the 2413 crosses, two crosses were sufficient for the determination of incompatibility. In 3.0 per cent of the crosses, the results for the two replicates differed, and in 1.6 per cent at least one of the flowers gave an ambiguous result (between three and 25 pollen tubes). Additional pollinations to verify the incompatibility relationships in these crosses resolved the results in all but three cases.

\section{Incompatibility types}

Results of full-diallel crosses allowed assignment of full-siblings into two to four incompatibility types for each sibship (Fig. 3, Table 1). Individuals having identical patterns of incompatibility were considered to be of the same incompatibility type. Figure 2 displays the results of all crosses for progeny in sibship 4, comprising four incompatibility types. Similar data from each of the 11 sibships are summarized in Fig. 3, showing the crossing relationships of incompatibility types. In sibships 6, 8 and 11 , individuals were assigned to incompatibility types on the basis of patterns observed in the majority of crosses, but anomalous results were found in 6,3 and 5 crosses, respectively.

In four of the 11 sibships $(2,6,10$ and 11), only two incompatibility types were found. Sibships 1 and 3 were found to contain three incompatibility types. The possibility that in these sibships a fourth type was expected but not sampled in the progeny array is discussed below. Sibships 4, 5, 7, 8 and 9 each

Table 1 Summary of results from sibling crosses in Linanthus parviflorus. Possible site of dominance was determined by computer analysis or, in sibships with two incompatibility types, by inspection of data (see text)

\begin{tabular}{|c|c|c|c|c|c|}
\hline Sibship & $\begin{array}{l}\text { No. of } \\
\text { progeny }\end{array}$ & $\begin{array}{c}\text { No. of } \\
\text { incompatibility } \\
\text { types }\end{array}$ & $\begin{array}{l}\text { Distribution of } \\
\text { incompatibility } \\
\text { types }\end{array}$ & $\begin{array}{l}\text { Reciprocal } \\
\text { differences }\end{array}$ & $\begin{array}{l}\text { Possible site of } \\
\text { dominance }\end{array}$ \\
\hline 2 & 16 & 2 & 10,6 & No & $\begin{array}{l}\text { Pollen only; stigma } \\
\text { only; both }\end{array}$ \\
\hline 6 & 16 & 2 & 9,7 & No & $\begin{array}{l}\text { Pollen only; stigma } \\
\text { only; both }\end{array}$ \\
\hline 10 & 12 & 2 & 6,6 & No & $\begin{array}{l}\text { Pollen only; stigma } \\
\text { only; both }\end{array}$ \\
\hline 11 & 17 & 2 & 8,9 & No & $\begin{array}{l}\text { Pollen only; stigma } \\
\text { only; both }\end{array}$ \\
\hline 3 & 16 & 3 & $7,5,4$ & Yes & Both \\
\hline $1^{*}$ & 11 & 4 & $6,3,2,0$ & Yes & $\begin{array}{l}\text { Pollen only; stigma } \\
\text { only; both }\end{array}$ \\
\hline 4 & 16 & 4 & $8,4,3,1$ & Yes & Stigma only; both \\
\hline 5 & 10 & 4 & $4,3,2,1$ & Yes & Stigma only; both \\
\hline $7 \dagger$ & 16 & 4 & $5,5,5,1$ & Yes & - \\
\hline 8 & 16 & 4 & $7,5,3,1$ & No & $\begin{array}{l}\text { Pollen only; stigma } \\
\text { only; both }\end{array}$ \\
\hline 9 & 15 & 4 & $7,3,3,2$ & Yes & Stigma only; both \\
\hline
\end{tabular}

${ }^{*}$ Results interpreted under the assumption that a fourth incompatibility type was expected but absent because of sampling error (see text).

$\dagger$ Results are not consistent with expectations for SSI with linear dominance. 

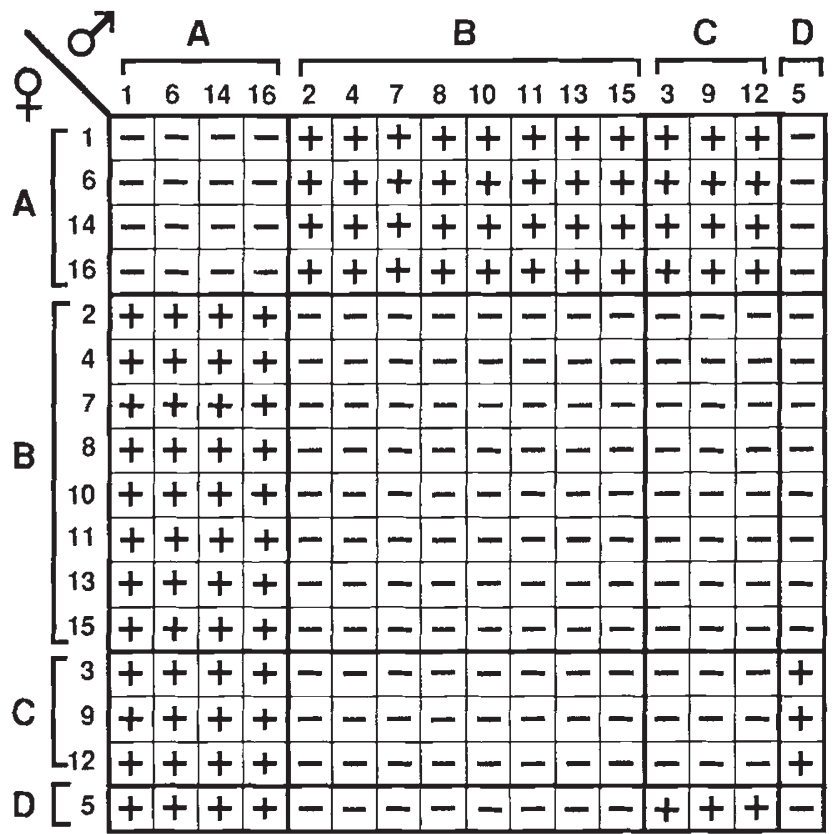

Fig. 2 Results of full-sibling diallel crosses for sibship 4. + denotes compatible cross; - denotes incompatible cross. Numbered progeny have been rearranged into incompatibility types, based upon crossing relationships.

contained four incompatibility types. In each of these sibships, at least one and sometimes two pairs of types were fully interincompatible.

\section{Reciprocal differences}

Of the seven sibships with three or four incompatibility types, all but one (sibship 8) exhibited reciprocal differences in incompatibility (Fig. 3, Table 1). In four of these (sibships 1, 3, 4 and 7), reciprocal differences were found in crosses between one pair of incompatibility types, and in sibships 5 and 9 , two cases of reciprocal differences were seen.

\section{Computer analysis}

The intertype incompatibility and reciprocal differences observed are inconsistent with GSI and suggest that SI in L. parviflorus is sporophytic. This interpretation is supported by the computer-aided analysis of the data, which indicated that incompatibility patterns for all but sibship 8 can be explained by SSI with linear dominance (Table 1). For sibships containing three incompatibility types (sibships 1 and 3), the program searched for dominance hierarchies to explain the observed incompatibilities both under the assumption that: (i) only three incompatibility types were expected because of dominance in $S$-alleles (Fig. 1c); and (ii) a fourth incompatibility type was missing in the progeny array because of sampling error. For sibship 1, solutions were found only when a fourth 'missing' incompatibility type was assumed to be absent. For sibship 3, solutions were found to explain the patterns of incompatibility under the assumption of either three or four expected incompatibility types. However, the observed distribution of incompatibility types deviates significantly from the expected Mendelian ratio under the assumption that an incompatibility type is missing in the sample (observed: $4: 5: 7: 0$ vs. expected: $4: 4: 4: 4$,
1

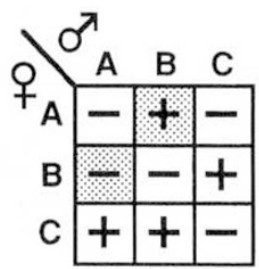

4

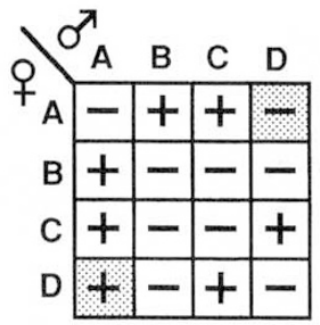

7

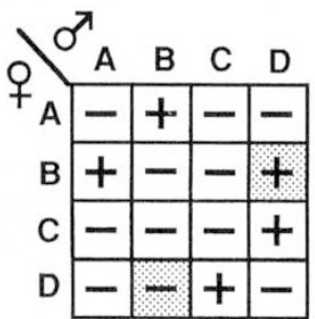

9

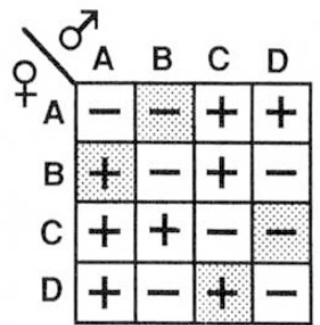

3

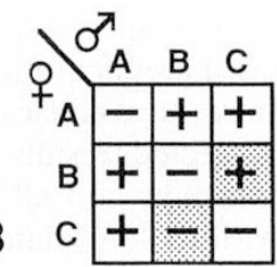

5
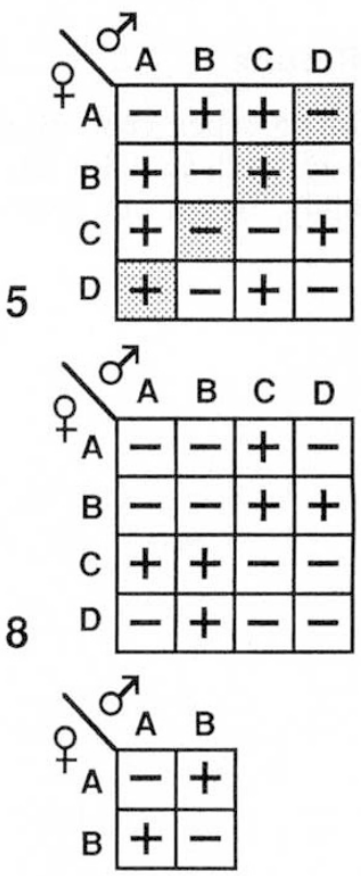

\section{$2,6,10,11$}

Fig. 3 Incompatibility types and their crossing relationships for sibships 1-11. + denotes compatible cross; denotes incompatible cross. Note that the incompatibility type designations $\mathrm{A}, \mathrm{B}, \mathrm{C}, \mathrm{D}$ are assigned arbitrarily and do not indicate a known correspondence among sibships. Reciprocal differences in incompatibility between types are indicated by shaded cells. 
$G=10.065, P<0.025$ ), whereas under the assumption that only three incompatibility types exist (the third incompatibility type comprising two genotypes) the observed distribution is not significantly different from expected (observed: $4: 5: 7$ vs. expected: $4: 4: 8$, $G=0.362, P>0.75)$. Thus it is likely that sibship 3 has only three expected incompatibility types. Results for sibships 4, 5, 8 and 9, with four incompatibility types each, can all be explained by SSI under a number of possible dominance hierarchies. Table 2 gives the solutions for sibship 4; the observed patterns of compatibility match those expected for three different dominance hierarchies, one with dominance in the stigma only and two with dominance in both tissues.

Incompatibility patterns in sibships $1,3,4,5,8$ and 9, as well as the sibships with only two incompatibility types, are consistent with expectations for dominance interactions in both stigma and pollen in which the hierarchy differs in the two tissues. In all but one instance, the incompatibility patterns could result from dominance expressed only in the stigma. The exception is sibship three where, under the assumption of three incompatibility types, all possible solutions involve dominance in both stigma and pollen.

Sibship 7 cannot be explained by any of the SSI models examined in the computer analysis. The rare incompatibility type (represented by a single individual) is incompatible with two other types and therefore must share one $S$-allele with each of them, eliminating the possibility that it contains a distinct contaminating $S$-allele from another pollen donor. The results for sibship 7 can be explained by a sporophytic model with nonlinear dominance.

\section{Discussion}

Linanthus parviflorus has been shown to have an effective SI system. The results of full-sibling crosses suggest that SI in L. parviflorus is sporophytic: (i) sibships contained four or fewer incompatibility types; (ii) some types were interincompatible; (iii) reciprocal differences in incompatibility among types were common; and (iv) patterns of incompatibility observed in all but one sibship can be explained by SSI with linear dominance.

\section{Incompatibility types}

Of the 11 sibships, four contained only two incompatibility types. This result is expected in SSI as a result of dominance or when one parent is homozygous at the $S$-locus, but it can also be explained by either GSI or SSI in the case where parents had an $S$-allele in common. The possibility that parents shared an $S$-allele cannot be eliminated in this study, although it seems unlikely to have occurred in as many as four out of 11 parental pairs. Seeds for the plants involved in parental crosses were collected at $>1 \mathrm{~m}$ intervals and, in a previous study of distancedependent incompatibility in a population of $L$. parviflorus, none of the crosses between plants $0.5 \mathrm{~m}$ apart ( $n=48$ pairs) was incompatible (C. Goodwillie, unpublished data), indicating substantial allelic diversity. However, because of the possibility of shared $S$-alleles in parental crosses, only the sibships with more than two incompatibility types provide conclusive evidence as to the genetic control of SI in L. parviflorus. A strong indication of SSI is the prevalence of intertype incompatibility in sibships with more than two incompatibility types. In GSI,

Table 2 Computer analysis for sibship 4 . The program generates all possible combinations of pollen and stigma dominance hierarchies in a sporophytic model that can explain the observed crossing relationships between incompatibility types (A-D), with $S_{1}$ always dominant to or codominant with $S_{2}$; $S_{2}$ dominant to or codominant with $S_{3}$, etc. For a given set of $S$-allele hierarchies, all possible genotypes for the incompatibility types are given. $=$ denotes codominance; $>$ denotes dominance

\begin{tabular}{llllll}
\hline \multicolumn{2}{l}{$\begin{array}{l}\text { Dominance hierarchy } \\
\text { Pollen }\end{array}$} & \multicolumn{4}{c}{ Stigma } \\
& \multicolumn{4}{c}{ Genotypes of incompatibility types } \\
\hline $1=2=3=4$ & $1=2>3>4$ & $\mathrm{~A}=(3,4)$ & $\mathrm{B}=(1,2)$ & $\mathrm{C}=(1,4)$ & $\mathrm{D}=(2,3)$ \\
$1=2=3=4$ & $1=2>3>4$ & $\mathrm{~A}=(3,4)$ & $\mathrm{B}=(1,2)$ & $\mathrm{C}=(2,4)$ & $\mathrm{D}=(1,3)$ \\
$1=2=3>4$ & $1=2>3=4$ & $\mathrm{~A}=(3,4)$ & $\mathrm{B}=(1,2)$ & $\mathrm{C}=(1,4)$ & $\mathrm{D}=(2,3)$ \\
$1=2=3>4$ & $1=2>3=4$ & $\mathrm{~A}=(3,4)$ & $\mathrm{B}=(1,2)$ & $\mathrm{C}=(2,4)$ & $\mathrm{D}=(1,3)$ \\
$1=2=3>4$ & $1=2>3>4$ & $\mathrm{~A}=(3,4)$ & $\mathrm{B}=(1,2)$ & $\mathrm{C}=(1,4)$ & $\mathrm{D}=(2,3)$ \\
$1=2=3>4$ & $1=2>3>4$ & $\mathrm{~A}=(3,4)$ & $\mathrm{B}=(1,2)$ & $\mathrm{C}=(2,4)$ & $\mathrm{D}=(1,3)$ \\
\hline
\end{tabular}


because pollen incompatibility has a haploid basis, plants are fully incompatible only with individuals of the same $S$-genotype, and therefore all incompatibility types are semi- or fully intercompatible. In SSI, dominance among $S$-alleles frequently results in full incompatibility among different types that share one $S$-allele.

\section{Site of dominance}

Numerous cases of reciprocal differences in compatibility among incompatibility types were found in the sibships (Table 1, Fig. 3). Reciprocal differences result from dominance relationships among $S$-alleles, a feature found only in SSI. Furthermore, its presence indicates that dominance relationships differ in the pollen and stigma. Analysis of crossing relationships in the sibships with three or more incompatibility types clearly eliminates the possibility that dominance is present only in pollen, as is true in composites (Crowe, 1954; Davidson \& Stace, 1986). All of the observed patterns of incompatibility are consistent with SSI models in which dominance is seen in both tissues, as well as models with dominance in the stigma only. It is likely that SSI in L. parviflorus is of the former type. If sibship 3 is assumed to contain three incompatibility types, which was seen to be the most likely explanation for the results observed, the crossing data are consistent only with models that involve dominance in both stigma and pollen. Furthermore, SSI systems with $S$-allele dominance in the stigma only have not been reported.

\section{Sl in the Polemoniaceae}

The incompatibility relationships of full-siblings found for $L$. parviflorus are not consistent with a one-locus gametophytic model, as has been described for $P$. drummondii (Levin, 1993). The data presented by Levin supporting the determination of one-locus GSI in Phlox consisted of seed-set data for crosses within self-sibling families generated by bud-pollinations. Patterns of compatibility among the heterozygote and two homozygote classes generated by selfing were used to distinguish between GSI and SSI. The expectations for compatibility for GSI differ from that for SSI in two of the nine possible crossing combinations among heterozygote and homozygote progeny classes. Levin reports that 24 of 34 self-sibships show incompatibility relationships consistent with GSI, but as in the data presented here for Linanthus, some of the sibships did not provide conclusive evidence as to the genetic basis of SI. Four of the remaining 10 families contained only two incompatibility types and were presumed to be missing one of the homozygote classes; patterns of incompatibility in these self-siblings are consistent with both GSI and with SSI with dominance in pollen expression. In three of the families, all crosses among self-siblings were incompatible, a pattern that suggests $S$-locus homozygosity in the parent plant. Some homozygosity is expected in SSI as a result of dominance, and it may occur in either type of system if leakiness in the SI mechanism allows occasional selfing to occur. Finally, three families showed compatibility in most crosses among siblings and cannot distinguish between GSI and SSI. Levin suggests these may indicate the presence of genes modifying $S$-locus activity.

Levin's results from self-sibships in $P$. drummondii and data reported here for full-siblings in L. parviflorus present contrasting evidence as to the genetic basis of SI in the Polemoniaceae. That these systems represent independent origins of SI within the Polemoniaceae seems unlikely for a number of reasons. SI systems must comprise a suite of complex mechanisms conferring recognition and inhibition, and involving expression in both pollen and stigma. It has been considered improbable that such a system would arise twice at the evolutionary timescale of divergence within a family, and no such cases are known (Matton et al., 1994). In addition, the SI mechanism appears to be physiologically similar in Linanthus and Phlox, with inhibition of incompatible pollen occurring at the stigma surface. The possibility exists that SSI in Linanthus evolved from GSI within the Polemoniaceae lineage. This type of transition in the evolution of SI has been proposed (Pandey, 1958, 1960) and has received recent consideration in explaining the presence of GSI and SSI, respectively, in the Solanaceae and Convolvulaceae, two closely related plant families (Matton et al., 1994). However, although evidence of this kind indicates that SI has arisen quite late in the evolution of the angiosperm families and suggests the possibility of relatively recent GSI to SSI transitions, the divergence of Linanthus and Phlox represents evolution on a much shorter timescale. In current molecular phylogenies of the Polemoniaceae (Steele \& Vilgalys, 1994; Johnson et al., 1996), Linanthus and Phlox are sister genera, indicating very recent divergence of these taxa within the family.

Evidence presented here for Linanthus is consistent with one-locus SSI and evidence of a different nature in Phlox is consistent with one-locus GSI. However, the possibility exists that a more complex 
model of SI can account for the compatibility patterns seen in both Phlox and Linanthus and may explain difficult-to-resolve features of both data sets (sibship 7 in this study, the three fully incompatible sibships in Levin's study, anomalous crossing results in both studies). Complex SI systems have been described in a number of taxa. GSI with two independently acting loci has been reported in the grasses (Lundqvist, 1956), and Pandey (1957) proposed a two-locus gametophytic SI system in Physalis ixocarpa (Solanaceae) in which epistatic interactions between the loci may differ in the stigma and pollen, resulting in reciprocal differences in incompatibility. However, because the expected number of incompatibility types in a sibship is generally higher than four in both of these two-locus gametophytic models, neither can account for the results seen in L. parviflorus. SI in Theobroma cacao results from a combination of sporophytically and gametophytically controlled mechanisms (Cope, 1962), and anomalous crossing results in brassicaceous species have led to the recent discovery of a locus with gametophytic action which complements the SSI mechanism (Lewis et al., 1988; Zuberi \& Lewis, 1988). The gametophytic mechanism in the Brassicaceae has been interpreted as a relict of an ancestral GSI system which continues to play some part in the pollen recognition system (Zuberi \& Lewis, 1988). The possibility that this type of complex system is present in the Polemoniaceae cannot be readily rejected, and demands further experimental testing.

The Polemoniaceae family has played an important role in the study of the ecology and evolution of plant reproduction. Interest has focused on its extraordinary diversity of pollination mechanisms and of breeding systems, ranging from autogamy to SI. Knowledge of the SI system in the Polemoniaceae contributes to our understanding of the reproductive biology of this important family. In light of the conflicting data for Linanthus and Phlox, whether they reflect two distinct SI mechanisms or can both be explained by a more complex system, further elucidation of the genetic control of SI in the Polemoniaceae will contribute to our general understanding of the evolution of SI.

\section{Acknowledgements}

I wish to thank Doug Schemske for helpful discussion through all phases of the project and manuscript preparation. Deborah Charlesworth and Adam Richman also supplied helpful comments on the manuscript. Doug Ewing provided expert green- house care of the plants. Thanks to Dan Ebert, who developed and wrote the computer program for analysis of crossing results, and to Juliette Winterer for suggesting the use of such a program. Copies of the program are available from the author upon request. This research was supported by a National Science Foundation predoctoral fellowship to the author and NSF grant DEB-9411869 to Doug Schemske and the author.

\section{References}

Bateman, A. J. 1954. Self-incompatibility systems in angiosperms. II. Iberis amara. Heredity, 8, 305-332.

BREWBAKER, J. L. 1957. Pollen cytology and incompatibility mechanisms in plants. J. Hered., 48, 271-277.

CAMPBell, D. R., WASER, N. M., PRICE, M. V., LYNCH, E. A. AND MITCHELL, R. J. 1991. Components of phenotypic selection: pollen export and flower corolla width in Ipomopsis aggregata. Evolution, 45, 1458-1467.

CHARLESWORTH, D. 1985. Distribution of dioecy and selfincompatibility in angiosperms. In: Greenwood, P. J., Harvey, P. H. and Slatkin, M. (eds) Evolution: Essays in Honour of John Maynard Smith, pp. 237-268. Cambridge University Press, Cambridge.

CHARLESWORTH, D. 1988. Evolution of homomorphic sporophytic self-incompatibility. Heredity, 60, 445-453.

COPE, F. W. 1962. The mechanism of pollen incompatibility in Theobroma cacao L. Heredity, 17, 157-182.

CROWE, L. K. 1954. Incompatibility in Cosmos bipinnatus. Heredity, 8, 1-11.

DAVIDSON, J. K. AND STACE, H. M. 1986. Genetics of selfincompatibility in Calotis cuneifolia. J. Hered., 77, 471-472.

FORD, M. A. AND KAY, Q. O. N. 1985. The genetics of incompatibility in Sinapis arvensis L. Heredity, 54, 99-102.

GALEN, C. AND STANTON, M. L. 1989. Bumble bee pollination and floral morphology: factors influencing pollen dispersal in the alpine sky pilot, Polemonium viscosum (Polemoniaceae). Am. J. Bot., 76, 419-426.

GERSTEL, D. U. 1950. Self-incompatibility studies in Guayule. II. Inheritance. Genetics, 35, 482-506.

GRANT, v. AND GRANT, K. A. 1965. Flower Pollination in the Phlox Family. Columbia University Press, New York.

HESLOP-HARRISON, J. AND SHIVANNA, K. R. 1977. The receptive surface of the angiosperm stigma. Ann. Bot., 41, 1233-1258.

hickman, J. c. (ed.) 1993. The Jepson Manual. Higher Plants of California. University of California Press, Berkeley.

sАСОВ, v. 1980. Pollination, fruit setting and incompatibility in Cola nitida. Incompatibility Newsletter, 12, $50-56$.

JOHNSON, L. A., SCHULTZ, J. L., SOLTIS, D. E. AND SOLTIS, P. s. 1996. Monophyly and generic relationships of Polemoniaceae based on matK sequences. Am. J. Bot., 83, $1207-1224$. 
KOWyama, Y., SHImano, N. AND Kawasi, T. 1980. Genetic analysis of incompatibility in the diploid species of Ipomoea closely related to the sweet potato. Theor. Appl. Genet., 58, 149-155.

LEVIN, D. A. 1972. Low frequency disadvantage in the exploitation of pollinators by corolla variants in Phlox. Am. Nat., 104, 455-467.

LEVIN, D. A. 1975. Gametophytic selection in Phlox. In: Mulcahy, D. L. (ed.) Gamete Competition in Plants and Animals, pp. 207-217. North Holland, Amsterdam.

LEVIN, D. A. 1993. S-gene polymorphism in Phlox drummondii. Heredity, 71, 193-198.

LEWIS, D., VERMA, S. C. AND ZUBERI, M. I. 1988. Gametophytic-sporophytic incompatibility in the CruciferaeRaphanus sativus. Heredity, 61, 355-366.

LUNDOVIST, A. 1956. Self-incompatibility in rye. I. Genetic control in the diploid. Hereditas, 42, 293-348.

LUNDQVIST, A. 1979. One-locus sporophytic self-incompatibility in the Carnation family, Caryophyllaceae. Hereditas, 91, 307 (Abstract).

LUNDOVIST, A. 1990. One-locus sporophytic $S$-gene system with traces of gametophytic pollen control in Cerastrium arvense ssp. strictum (Caryophyllaceae). Hereditas, 113, 203-215.

MARTIN, F. w. 1959. Staining and observing pollen tubes in the style by means of fluorescence. Stain Technol., 34, $125-128$.

MARTIN, F. w. 1968. The system of self-incompatibility in Ipomoea. J. Hered, 59, 263-267.

MATTON, D. P., NASS, N., CLARKE, A. E. AND NEWBIGIN, E. 1994. Self-incompatibility: how plants avoid illegitimate offspring. Proc. Natl. Acad. Sci. U.S.A., 91, 1992-1997.

DE NETTANCOURT, D. 1977. Incompatibility in Angiosperms. Springer-Verlag, Berlin.
OCKENDON, D. J. 1974. Distribution of self-incompatibility alleles and breeding structure of open-pollinated cultivars of brussels sprouts. Heredity, 33, 159-171.

PANDEY, K. K. 1957. Genetics of self-incompatibility in Physalis ixocarpa Brot. A new system. Am. J. Bot., 44, 879-887.

PANDEY, K. K. 1958. Time of $S$-allele action. Nature, 181, $1220-1221$.

PANDEY, K. K. 1960. Evolution of gametophytic and sporophytic systems of self-incompatibility in angiosperms. Evolution, 14, 98-115.

RICHARds, A. J. 1986. Plant Breeding Systems. Allen \& Unwin, London.

SAMPSON, D. R. 1958. The genetics of self-incompatibility in Lesquerella densipila and in the $F_{1}$ hybrid $L$. densipila $\times$ L. Lescurii. Can. J. Bot., 36, 39-56.

SCHOEN, D. J. 1982. The breeding system of Gilia achilleifolia: variation in floral characteristics and outcrossing rate. Evolution, 36, 352-360.

STEELE, K. P. AND VIlgalys, R. 1994. Phylogenetic analyses of Polemoniaceae using nucleotide sequences of the plastid gene matK. Syst. Bot., 19, 126-142.

THOMPSON, K. F. AND TAYLOR, J. P. 1966. Non-linear dominance relationships between $S$ alleles. Heredity, 21, 345-362.

THOMPSON, M. T. 1979. Genetics of incompatibility in Corylus avellana L. Theor. Appl. Genet., 54, 113-116.

UYENOYAMA, M. K. 1995. A generalized least-squares estimate for the origin of sporophytic self-incompatibility. Genetics, 139, 975-992.

ZUBERI, M. I. AND LEWIS, D. 1988. Gametophytic-sporophytic incompatibility in the Cruciferae--Brassica campestris. Heredity, 61, 367-377. 